\title{
Prevalência de hemoglobina S em recém-nascidos de Fortaleza: importância da investigação neonatal
}

\author{
The prevalence of hemoglobin S in newborns from Fortaleza, Brazil: \\ The importance of neonatal research
}

\begin{abstract}
Luciano Silveira Pinheiro ${ }^{1}$, Romélia Pinheiro Gonçalves ${ }^{2}$, Carlos Alberto Sousa Tomé ${ }^{3}$, Ana Elisa Evangelista Alcântara ${ }^{4}$, Anna Renée Cintra Marques ${ }^{5}$, Márcio Medeiros da Silva ${ }^{6}$
\end{abstract}

\section{RESUM0}

Objetivos: avaliar a prevalência de hemoglobina $\mathrm{S}$ (HbS, traços falciformes) em recém-nascidos, por meio de investigação clínico-laboratorial. Métodos: foi elaborado protocolo que estabelece a coleta de $10 \mathrm{~mL}$ de sangue de segmento de cordão umbilical, após ser ligado e seccionado pelo obstetra em seguida ao parto, sendo as amostras introduzidas em um tubo contendo EDTA a 5\% e submetidas a estudo cromatográfico líquido de alta resolução (high-performance liquid chromatography). Preenchia-se também protocolo clínico mediante entrevista com a puérpera, analisava-se o seu prontuário e efetuava-se o exame físico do recém-nascido. As variáveis analisadas foram peso do recém-nascido, sexo, Apgar no primeiro minuto e cor da mãe. A análise estatística foi baseada no programa Epi-Info versão 6.0, utilizando-se o teste $t$ de Student, considerando-se o nível de significância de $\mathrm{p}<0,05$. Resultados: no período de agosto de 2001 a setembro de 2002 , foram analisadas 389 amostras de sangue de cordão umbilical e identificada a presença de HbS em 16 recém-nascidos (4,1\%), 15 dos quais compatíveis com traços falcêmicos (HbAS) e um com a hipótese diagnóstica de anemia falciforme (HbSS). Observou-se maior prevalência de hemoglobinopatia no sexo masculino. Não houve diferença significante entre os recémnascidos com ou sem HbS para médias de peso e escores de Apgar, assim como para cor de pele das mães (brancas, pardas e negras). Conclusão: recomenda-se triagem de hemoglobinopatias em recém-nascidos, tendo em vista a possibilidade da ocorrência de $25 \%$ da anemia falciforme nos filhos de casais com ambos os cônjuges apresentando traços falcêmicos. Diante disso, sugere-se a implantação de programas com esses objetivos e incorporação às rotinas hospitalares.

PALAVRAS-CHAVE: Hemoglobina falciforme; Hemoglobinopatias; Anemia falciforme; Recém-nascido

\section{ABSTRACT}

Purpose: to evaluate the prevalence of hemoglobin $\mathrm{S}(\mathrm{HbS})$ in newborns, through clinical investigation and laboratory data. Methods: a protocol established the drawing of $10 \mathrm{~mL}$ blood from the umbilical cord after its ligature and section, immediately after birth. The samples were kept in a tube with 5\% EDTA and then submitted to high-performance liquid chromatography. The study included a clinical record taken from an interview with the mother, her physical and biochemical condition, as well as that of her newborn. Main criteria were newborn's weight, sex, first minute Apgar, and the mother's color. Statistical analysis was based on the Epi-Info 6.0 program and performed by Student's $t$ test, with the level of significance set at $p<0.05$. Results: from August 2001 to September 2002, 389 umbilical cord blood samples showed HbS in 16 newborn babies (4.1\%). Fifteen of these presented sickle-cell traits (HbS) and the other had a diagnostic hypothesis of sickle-cell anemia (HbSS). Hemoglobinopathy prevailed among male babies. No significant difference was observed between newborns with or without HbS regarding averages of weight and Apgar scores; the same occurred regarding the mother's skin color (Caucasians, mulattos and blacks). Conclusion: searching for hemoglobin diseases in newborns should be considered because of the possibility of $25 \%$ sicklecell anemia in the offspring of couples with sickle-cell traits. Screening for abnormal hemoglobin is important in the population at risk. Thus, the creation of programs with these aims is recommended to be included in hospital routines.

KEYWORDS: Hemoglobin, sickle; Hemoglobinopathies; Anemia, sickle cell; Infant, newborn

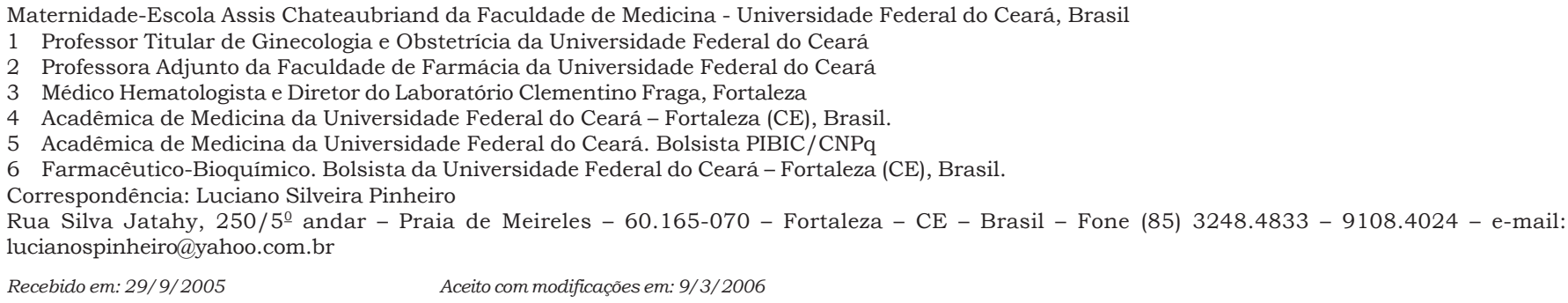


Introdução

A anemia falciforme é provavelmente a doença hematológica hereditária mais prevalente na população brasileira ${ }^{1}$. Tendo se originado na África e trazida à América pela imigração forçada dos escravos, é mais freqüente onde a proporção de antepassados negros é maior. A doença distribuiu-se heterogeneamente no Brasil em virtude da miscigenação racial, favorecendo assim a continuidade dessa anemia no país e sendo apontada pela literatura científica brasileira como grave problema de saúde pública. A etiologia dessa doença decorre de mutação no gene da globina beta, que produz uma hemoglobina anormal, denominada hemoglobina S (HbS, traço falciforme), cuja alteração estrutural é responsável por modificações da estabilidade e solubilidade moleculares ${ }^{2}$ e conseqüente falcização dos eritrócitos quando expostos à baixa tensão de oxigênio, acidose ou desidratação ${ }^{3}$.

Quando o indivíduo é homozigoto para a mutação falciforme, quase toda a hemoglobina em seus eritrócitos consiste em $\mathrm{HbS}$, levando ao quadro clínico totalmente manifesto. No heterozigoto, apenas cerca de $40 \%$ das hemoglobinas são constituídas por $\mathrm{HbS}$, sendo o restante representado por moléculas de hemoglobinas normais, o que inibe o processo de falcização. Por conseguinte, esses indivíduos têm pouca tendência ao afoiçamento, exceto em condições de grave hipóxia ${ }^{4}$. Durante a vida fetal e início da pós-natal, a falta de expressão do fenótipo HbSS é explicada pela produção de hemoglobina fetal $(\mathrm{HbF})$ suficiente para limitar, por efeito diluidor, a falcização clinicamente importante. Como os eritrócitos que emergem da medula óssea transportam quantidades crescentes de $\mathrm{HbS}$ e quantidades reduzidas de $\mathrm{HbF}$, as condições para a falcização são alcançadas gradualmente ${ }^{5}$. Portanto, os recém-nascidos começam a manifestar a doença a partir do sexto mês de vida, quando a quantidade de $\mathrm{HbF}$ começa a aproximar-se dos níveis do adulto ${ }^{6}$.

Considerando a gravidade e a freqüência da anemia falciforme, é importante aceitar-se que o diagnóstico precoce é fundamental, uma vez que a identificação neonatal dos pacientes portadores da hemoglobinopatia irá permitir abordagem adequada nos primeiros anos de vida e aconselhamento genético, reduzindo as complicações decorrentes da doença ${ }^{7,8}$.

Não obstante a anemia falciforme estar sendo muito estudada no Brasil quanto à sua incidência e distribuição em diferentes regiões e grupos raciais, essas investigações têm utilizado na maioria das vezes metodologia manual, como é o caso da eletroforese em $\mathrm{pH}$ alcalino e em $\mathrm{pH}$ ácido, o diagnóstico de $\mathrm{HbS}$ no período neonatal sendo dificultado pela presença de grande quantidade de $\mathrm{HbF}^{1}$. Apesar disso, mesmo com esses óbices, até o momento atual são poucos os trabalhos referentes ao diagnóstico neonatal por meio da cromatografia líquida de alta resolução (high-performance liquid chromatography, HPLC) ${ }^{9}$.

O método cromatográfico automatizado apresenta vantagens sobre a eletroforese tanto em $\mathrm{pH}$ alcalino, quanto em $\mathrm{pH}$ ácido, uma vez que mostra maior sensibilidade e rapidez para identificação das frações de hemoglobinas, com quantificação e resultados precisos, fornecendo ainda dados qualitativos das hemoglobinas variantes, mesmo que estas estejam em pequenas quantidades ${ }^{10}$. Portanto, considerando a importância do tema, a presente investigação teve como objetivo avaliar a prevalência da $\mathrm{HbS}$ em amostras de sangue de cordão umbilical de recém-nascidos, utilizando-se a metodologia HPLC.

\section{Métodos}

Foi realizado estudo prospectivo, a partir de um protocolo ${ }^{11}$ que estabelece a coleta de $10 \mathrm{~mL}$ de sangue de segmento de 15 a $20 \mathrm{~cm}$ de cordão umbilical, após ligado e seccionado pelo obstetra em seguida ao parto (vaginal ou cesariano), de 389 recém-nascidos seqüencialmente assistidos na Maternidade-Escola Assis Chateaubriand (Fortaleza), no período de agosto de 2001 a setembro de 2002. O segmento do cordão umbilical com as dimensões mencionadas é suspenso pelas extremidades com ajuda de pinças de Kelly, sendo o sangue introduzido de imediato, por gotejamento, com o afrouxamento da pinça da extremidade inferior, sem ordenha, em tubo contendo EDTA a 5\%.

As amostras de sangue coletadas eram encaminhadas para HPLC, processamento que utiliza o equipamento Bio-Rad, sistema automatizado Variant $\mathrm{II}^{\circledR}$ (Hercules, CA, USA). O equipamento dispõe de diferentes protocolos, sendo utilizado, para fins de triagem neonatal, o programa para anemia falciforme. As amostras são diluídas em reagente e mantidas a $12^{\circ} \mathrm{C}$ em câmara automática. Cada amostra é seqüencialmente injetada no sistema de fluxo de análise a cada três minutos, favorecendo rápida análise. Um fotômetro de filtro com comprimento de onda dupla (415 e 690 $\mathrm{nm})$ monitora a eluição de hemoglobina da coluna, detectando as alterações de absorbância a 415 $\mathrm{nm}$. O filtro secundário de $690 \mathrm{~nm}$ corrige a linha de base para efeitos provocados pela mistura dos tampões com forças iônicas diferentes. As mudanças das absorbâncias são monitoradas e exibidas na forma de cromatograma da absorbância versus tempo. Cada hemoglobina apresenta tempo de retenção característico. Ao final da análise de cada amostra, uma cópia do cromatograma com dados do relatório é automaticamente impressa ${ }^{9,10}$.

Após cada coleta preenchia-se um protocolo clínico, constando de entrevista com a puérpera, aná- 
lise do seu prontuário e exame físico do recém-nascido. Foram incluídos na investigação os recém-nascidos provenientes de gravidezes com 22 a 42 semanas incompletas e excluídos os oriundos de prenhezes com intercorrências de infecção intraparto grave e sofrimento fetal. Utilizou-se o teste " $\mathrm{t}$ " de Student para cotejamento das médias dos pesos e o teste Qui-quadrado para análise da freqüência da ocorrência de recém-nascidos com alterações hemoglobínicas e correlação com a raça das mães. Foi utilizado o cálculo da mediana na avaliação dos escores de Apgar dos grupos fetais estudados. As mães dos recém-nascidos foram classificadas em pardas, brancas e negras, lavando-se em consideração a cor da pele e olhos, espessura dos lábios e características do cabelo ${ }^{12}$.

A análise estatística foi realizada a partir da elaboração de banco de dados do programa Epi-Info, versão 6.0, considerando-se o nível de significância de $\mathrm{p}<0,05$, sendo utilizado o teste $t$ de Student.

Esta investigação foi aprovada pelo Comitê de Ética em Pesquisa da Faculdade de Medicina da Universidade Federal do Ceará e realizada após assinatura do Termo de Consentimento, pelas mães dos recém-nascidos.

\section{Resultados}

No período de agosto de 2001 a setembro de 2002, foram analisadas 389 amostras de sangue de cordão umbilical. Os resultados obtidos detectaram que 16 recém-nascidos (4,1\%) mostraram presença de $\mathrm{HbS}, 15$ dos quais sugestivos de traço falcêmico (HbAS), correspondendo a 3,8\% do total, e um com a hipótese diagnóstica de anemia falciforme $\mathrm{HbSS}(0,2 \%)$. Foi observado que dos 200 recém-nascidos do sexo feminino, 2,0\% apresentaram $\mathrm{HbS}$, e que dos 189 do sexo masculino, $6,3 \%$ apresentaram hemoglobina alterada (Tabela 1).

Tabela 1 - Distribuição das formas de hemoglobina e variantes e do sexo fetal em 389 amostras de sangue de recém-nascidos

\begin{tabular}{lcc}
\hline Características da amostra & $\mathbf{n}$ & $\%$ \\
\hline Hb normal $(\mathrm{HbA})$ & $373 / 389$ & 96 \\
HbAS & $15 / 389$ & 3,8 \\
HbSS & $1 / 389$ & 0,2 \\
RN feminino c/ hemoglobinopatia & $4 / 200$ & 2,0 \\
RN masculino c/ hemoglobinopatia & $12 / 189$ & 6,3 \\
\hline
\end{tabular}

A partir da avaliação neonatal, encontrou-se que o peso dos recém-nascidos sem hemoglobinopatias variou de 570 a $5.445 \mathrm{~g}$, com a média de 3.187 $\mathrm{g}$, e dos recém-nascidos com hemoglobina anormal, a variação foi de 1.725 a $3.790 \mathrm{~g}$, com a média de $2.853 \mathrm{~g}$, não havendo diferença significante entre os dois grupos ponderais. Quanto à avaliação do Apgar, evidenciou-se que o valor no primeiro mi- nuto dos recém-nascidos com alteração e sem alteração na hemoglobina foi de 7 . Baseando-se nos critérios estabelecidos ${ }^{12}$, observaram-se $60,9 \%$ de mães pardas, $23,0 \%$ brancas e $16,1 \%$ de negras. As hemoglobinas alteradas apresentaram-se em 5,6, 2,3 e 1,6\% entre os filhos de mães pardas, brancas e negras, respectivamente.

\section{Discussão}

Examinando-se 389 amostras de sangue de cordão umbilical de recém-nascidos com o emprego da eletroforese por HPLC, encontramos a prevalência de 4,1\% de portadores de HbS. Esses dados estão de acordo com os do Ministério da Saúde, segundo o qual a prevalência do gene da doença falciforme na população varia de 4 a $6 \%$ na região Nordeste brasileira ${ }^{2}$.

$\mathrm{Na}$ literatura relativa aos dados brasileiros, podem-se citar alguns trabalhos de diagnóstico neonatal de hemoglobinopatias: um no Hospital de Base de São José do Rio Preto (SP) ${ }^{13}$, outro no Instituto Materno-Infantil de Pernambuco ${ }^{1}$ e, finalmente, os resultados do programa de triagem neonatal para hemoglobinopatias do HEMORIO ${ }^{9}$. No estudo realizado em São José do Rio Preto foram analisadas por meio de eletroforese em pH alcalino 913 amostras de sangue de cordão umbilical, e 3,7\% dos recémnascidos incluídos apresentaram traços de HbS. Na avaliação de 1.988 amostras de sangue de cordão umbilical realizada em Pernambuco, com o emprego também de eletroforese em $\mathrm{pH}$ alcalino, encontrou-se que 5,3\% dos recém-nascidos apresentaram HbS. Já na investigação ocorrida no estado do Rio de Janeiro, no período de agosto de 2000 a novembro de 2001, foi observada a presença de 4.663 neonatos $(4,7 \%)$ portadores de traço falciforme (HbAS), tendo sido estudadas 99.260 crianças por HPLC.

Embora sabendo-se que o gene que codifica a $§$ globina na HbS não está ligado ao sexo, observase no presente estudo que os recém-nascidos do sexo masculino apresentaram prevalência maior de HbS que os recém-nascidos do sexo feminino, assim como no trabalho realizado no Laboratório Campana, no qual foram analisadas 1.303 amostras de sangue de recém-nascidos, utilizando eletroforese da hemoglobina em $\mathrm{pH}$ alcalino ${ }^{14}$.

Com relação à média de peso e valor de Apgar dos recém-nascidos normais, quando comparados aos dos recém-nascidos portadores de hemoglobinopatias, observou-se que não houve diferença significante entre os grupos. Portanto, os resultados obtidos neste estudo estão de acordo com os dados encontrados na literatura, segundo os quais a presença de $\mathrm{HbS}$ não se apresenta como fator de risco para as condições de nascimento, como baixo peso e menores índices de Apgar ${ }^{1}$. 
Ao se cotejar a presença de hemoglobinas anormais com a cor da mãe, obedecendo-se a critérios estabelecidos previamente, não se evidenciou diferença entre as mães de cor negra, parda ou branca. Esse fato confirma a miscigenação ocorrida no Brasil, particularmente no Ceará. Desse modo, acreditamos que no nosso meio, a triagem de hemoglobinopatias não deve ser feita baseando-se na cor da mãe a fim de determinar quais os recém-nascidos que irão submeter-se ao procedimento.

Quanto ao método utilizado para detectar hemoglobinas anormais, a cromatografia líquida automatizada de alta resolução, de troca de íons $(\text { HPLC })^{10}$, vem sendo cada vez mais usada ${ }^{9}$, apresentando quatro vantagens sobre a eletroforese convencional: o analisador é automatizado, economizando horas e trabalho, permitindo o processamento de muito mais amostras; trabalha com volumes insignificantes da amostra (5 microlitros), o que é particularmente útil em Neonatologia, e as hemoglobinas normais e todas as variantes identificadas são simultaneamente quantificadas. Além disso, fornece identificação provisória de número maior de variantes hemoglobínicas.

A prevalência de HbS entre os 389 recém-nascidos estudados foi relativamente alta e compativel com resultados encontrados em outras investigações realizadas no Brasil e no exterior, sendo relevante recomendar a triagem de hemoglobinopatias em recém-nascidos como primeiro passo para reduzir a morbimortalidade dos indivíduos com doença falciforme, além de possibilitar o diagnóstico de heterozigotos e o aconselhamento genético, fornecendo subsídios para que os portadores decidam conscientemente sobre sua prole futura. Além disso, a exemplo do Rio de Janeiro ${ }^{9}$ e da Inglaterra ${ }^{15,16}$, é fácil conscientizarse que a implementação de programa de triagem neonatal configura-se importante para a identificação precoce dos portadores, realização de aconselhamento genético dos pais, informando-os sobre a chance de virem a ter outros filhos afetados, bem como orientando-os sobre os sinais e sintomas precoces das complicações e identificação de outros portadores no grupo familiar. Sugere-se, portanto, que esse tipo de triagem seja incluído em programas de saúde e incorporado às rotinas hospitalares, possibilitando a prevenção das complicações, aumentando a sobrevida e melhorando a qualidade de vida dos pacientes portadores de hemoglobinopatias, tendo em vista também saber-se da possibilidade da ocorrência de $25 \%$ de anemia falciforme nos filhos de casais com ambos os cônjuges apresentando traços falcêmicos.

\section{Referências}

1. Bandeira FMGC, Leal MC, Souza RR, Furtado VC, Gomes YM, Marques NM. Características de recém- nascidos portadores de hemoglobina $\mathrm{S}$ detectados através de triagem em sangue de cordão umbilical. J Pediatr (Rio de J). 1999;75(3):167-71.

2. Agência Nacional de Vigilância Sanitária (ANVISA). Manual de diagnóstico e tratamento das doenças falciformes. Brasília: Ministério da Saúde; 2002.

3. Tomé-Alves R, Marchi-Salvador DP, Orlando GM, Palharini LA, Imperial RE, Naoum PC, BoniniDomingos CR. Hemoglobinas AS/alfa talassemia: importância diagnóstica. Rev Bras Hematol Hemoter. 2000;22(3):388-94.

4. Aster JC. Red blood cell and bleeding disorders. In: Kumar V, Abbas A, Fausto N, editors. Robbins and Cotran pathologic basis of disease. $7^{\text {th }}$ ed. Philadelphia: Elsevier/Saunders; 2004. p. 619-59.

5. Wang WC. Sickle cell anemia and other sickling syndromes. In: Greer JP, Foerster J, Lukens JN, editors. Wintrobe's clinical hematology. $11^{\text {th }}$ ed. Philadelphia: Lippincott Williams \& Wilkins; 2004. p. 2000-80.

6. Vichinsky E, Hurst D, Earles A, Kleman K, Lubin B. Newborn screening for sickle cell disease: effect on mortality. Pediatrics. 1988;81(6):749-55.

7. Smith JA, Kinney TR. Sickle cell disease: screening and management in newborns and infants. Am Fam Physician. 1993;48(1):95-102.

8. Galacteros F. Diagnostic néonatal des hemoglobinopathies. Rev Prat. 1992;42(15):1893-5.

9. Lobo CLC, Bueno LM, Moura P, Ogeda LL, Castilho $\mathrm{S}$, Carvalho SMF. Triagem neonatal para hemoglobinopatias no Rio de Janeiro, Brasil. Rev Panam Salud Pública. 2003;13(2-3):154-9.

10. Lewis SM, Bain BJ, Bates I. Hematologia prática de Dacie e Lewis. 9a ed. Porto Alegre: Artmed; 2006. p. 229-48.

11. Pinheiro LS, Pinheiro RG, Tomé CA, Alcântara AEE, Macedo CA, Marques ARC, et al. Padronização de método de coleta de sangue do cordão umbilical de recém-nascidos na Maternidade-Escola da Universidade Federal do Ceará. Nota Prévia. Obstet Ginecol España. 2001;10(1):97-9.

12. Daudt LE, Zechmaister D, Portal L, Camargo Neto E, Silla LMR, Giugliani R. Triagem neonatal para hemoglobinopatias: um estudo piloto em Porto Alegre, Rio Grande do Sul, Brasil. Cad Saúde Pública. 2002;18(3):833-41.

13. Ducatti RP, Teixeira AEA, Galão HA, Bonini-Domingos $\mathrm{CR}$, Fett-Conte AC. Investigação de hemoglobinopatias em sangue de cordão umbilical de recém-nascidos do Hospital de Base de São José do Rio Preto. Rev Bras Hematol Hemoter. 2001;23(1):23-9.

14. Campana PGC, Campana GA, Ari J. Prevalência de hemoglobinopatias no Laboratório Campana. NewsLab. 2001;49(3):100-10.

15. Almeida AM, Henthorn JS, Davies SC. Neonatal screening for haemoglobinopathies: the results of a 10-year programme in an English Health Region. Br J Haematol. 2001;112(1):32-5.

16. Henthorn JS, Almeida AM, Davies SC. Neonatal screening for sickle cell disorders. Br J Haematol. 2004;124(3):259-63. 